\title{
Sensibilidades arquitectónicas en la Confederación Argentina. La decoración para el chateaux del soberano moderno y la didáctica del orden arquitectónico para educar en el buen gusto. Concepción del Uruguay y Paraná, 1854 -1859
}

\author{
Architectural sensibilities in the Argentine Confederation The chateaux decor for \\ the modern sovereign and the principals of the architectural order, to educate on \\ the good taste. Concepción del Uruguay and Paraná, 1854-1859
}

\author{
Silvia Dócola \\ silviadocola@hotmail.com \\ Facultad de Arquitectura, Planeamiento y Diseño. \\ Consejo de Investigaciones. Universidad Nacional \\ Rosario., Argentina
}

Recepción: 03 Agosto 2020

Aprobación: 09 Septiembre 2020

Publicación: 13 Noviembre 2020

Cita sugerida: Dócola, S. (2020). Sensibilidades arquitectónicas en la Confederación Argentina. La decoración para el chateaux del soberano moderno y la didáctica del orden arquitectónico para educar en el buen gusto. Concepción del Uruguay y Paraná, 1854 -1859. Anuario del Instituto de Historia Argentina, 20(2), e123. https://doi.org/10.24215/2314257Xe123
Resumen: Este artículo propone una lectura de cómo se operó desde el "buen gusto" para proyectar espacios de poder diferenciados, que fortalecieran y legitimaran el proyecto político de la Confederación Argentina bajo la presidencia de Justo José de Urquiza. Se examina la manera en que Urquiza desarrolló cierta "sensibilidad arquitectónica" para proyectar su espacio contratando a Pietro Fossati, quien, mediante el manejo de los criterios beaux-arts, convirtió la casa del caudillo en el lugar del soberano moderno. Mientras que, para la construcción de la capital de la Confederación, Santiago Danucio construyó fachadas urbanas para hacer visible los poderes del Estado, y, de ese modo, generar cierta didáctica del buen gusto, mediante la utilización de los elementos y reglas de la antigüedad clásica.

Palabras clave: Arquitectura, Fossati, Danucio, Confederación Argentina, Urquiza.

\begin{abstract}
This article proposes a reading on how "good taste" was the basis to plan power spaces that would strengthen and legitimize the political project of the Argentine Confederation under the presidency of Justo José de Urquiza. It is examined the way in which Urquiza developed certain architectural sensibility to plan his space, therefore employing Pietro Fossati, who through the beaux-arts criteria transformed the house of Urquiza into the place of a modern sovereign. As for the design of the capital city, Santiago Danucio built urban facades to demonstrate the authority of the government. Thus, generating certain good taste principals, through the use of classical antiquity elements and rules.
\end{abstract}

Keywords: Architecture, Fossati, Danucio, Argentine Confederation, Urquiza. 


\section{INTRODUCCIÓN}

La Confederación Argentina $(1852$ - 1861) se proyectó como un Estado federativo de base capitalista. En casi todo el arco de tiempo que tuvo vigencia, la provincia de Buenos Aires estuvo escindida. Ante la pérdida de la ciudad de Buenos Aires, como centro - puerto y sede política e intelectual- y el desafío de construir un Estado, el poder se descentró en tres espacios diferentes: dos aldeas sobre el Paraná y un espacio extendido sobre el río Uruguay. Se definió entonces a Paraná como capital transitoria y centro político de la Confederación, a Rosario como puerto de las Provincias, y al área sobre el río Uruguay entre San José, Concepción y Santa Cándida, como el espacio de Urquiza.

Urquiza, frente a una aparente falta de educación en el gusto, desarrolló cierta sensibilidad arquitectónica. Por una parte, para proyectar su espacio identitario contrató a Fossati, un arquitecto formado, quien mediante el manejo de los criterios beaux-arts convirtió la casa del caudillo en el lugar del soberano moderno. Para la construcción de la capital, en cambio, recurrió a Danucio, "un fiel federal”, que resolvió proyectar fachadas para hacer visible el poder del Estado, y, de ese modo, generar en los visitantes de Paraná cierta sensibilidad arquitectónica, una didáctica del "buen gusto", mediante la utilización de los elementos y reglas de la antigüedad clásica.

En este sentido, la Arquitectura como disciplina admite un análisis centrado en la edificación de los espacios desde los que se legitimó y visibilizó el poder. Las nuevas arquitecturas proponen un cambio en ciertas conductas, pero, sobre todo, asumimos a la arquitectura (entendida como disciplina que opera con el espacio físico) como una estrategia que permite hacer visible el poder. Tirado y Mora afirman:

el poder que produce es un poder que exhibe, que opera liberando las cosas en el terreno de la visión, exponiéndola ante la mirada, sustrayéndola al secreto y a la oscuridad. Para arrojarla a la luz, ante el ojo, delante del ojo. Por lo tanto, poder es exhibir. Poder es hacer ver. El poder libera las cosas en el campo de la visión: es exposición (Tirado y Mora, 2002, p. 19).

En este artículo analizamos cómo a partir de la producción de espacios se buscó hacer visible el poder. En términos de sensibilidad política, si Urquiza quería dejar de ser visualizado como un caudillo y pasar a ser reconocido como un hombre civilizado, un hombre republicano y un empresario capitalista, fue de utilidad demostrar que había cambiado su sensibilidad estética. Si los hombres de Paraná querían hacer visible y legitimar a la Confederación Argentina a través de la construcción de los espacios de la República, apostaron a hacerlo apelando a ciertas normas del buen gusto. A la vez, estas nuevas arquitecturas y sus representaciones tenían por objetivo generar, sobre todo en Europa, una nueva imagen de Urquiza y del nuevo proyecto de la Confederación Argentina.

El problema que tuvieron que enfrentar quienes pretendían dar forma a estos nuevos espacios de poder fue la falta de técnicos formados. Carlo Zucchi, un arquitecto italiano que operó en Buenos Aires y Montevideo entre 1826 y 1842, realizó en 1828 un diagnóstico sobre el estado de las “artes” en los Estados del Plata. ${ }^{1}$ En ella aseveraba que a los habitantes del Plata, "el interés y el buen gusto por las Bellas Artes les debiera entrar a sus cuerpos por milagro” (Aliata, 2009, p. 187). Además, los pocos profesionales que había solo se instalaban en Buenos Aires y Montevideo. En el interior prevalecían los idóneos; a los comitentes en general solo les bastaba quien supiera continuar con una tradición constructiva. En una carta escrita por Agustín Justo de la Vega, el recientemente electo gobernador de Tucumán, a Tomás Guido -en febrero de 1857- queda clara esta posición. Guido había recomendado un arquitecto para que trabajase en dicha ciudad, el gobernador en su respuesta se disculpa: "aquí se edifica extraordinariamente, pero el gusto no se halla tan adelantado como para que un arquitecto de esa clase pueda tener una ocupación constante y lucrativa" (De la Vega, 1857, $\mathrm{f}$. 169). Al decir de De la Vega, es una cuestión de falta de gusto o poco desarrollo del gusto hacia la arquitectura por parte de los comitentes, lo que coincide con el diagnóstico que Zucchi había hecho treinta años antes.

Con educación en el buen gusto nos referimos a una idea compartida por la estética empirista como capacidad para percibir belleza, con aspiraciones de universalidad. Como ha desarrollado Pérez Alonso 
(2008), hacia fines del siglo XVIII e inicios del XIX la teoría del gusto intentó explicar el placer o displacer que sentimos ante lo estético. La educación en el gusto se constituía en una preocupación. En ese sentido, el bien, la verdad y la belleza eran consideradas ideas universales y absolutas, que debían ser aprehendidas por todo aquel que no gozara de suficiente refinamiento en su buen gusto. Para esta teoría, quien no tuviera desarrollada esta sensibilidad de manera natural podía ser educado. La construcción de los edificios de poder, tanto en Paraná como en Concepción, puede pensarse como un ejemplo para educar en el buen gusto, una especie de didáctica de sensibilidad arquitectónica desde la que se proyectaba una moral republicana.

\section{UN CHATEAUX PARA UN SOBERANO. LA DECORACIÓN PARA CAMBIAR LA IMAGEN DE URQUIZA}

Urquiza puede pensarse como un sujeto que manejaba diversas estrategias entre las que se conjugaron la vieja figura de un caudillo (estanciero, militar), y, a la vez, la figura del líder que llevaba adelante pautas programáticas modernas para la construcción de una república bajo el formato de un capitalismo agrario. Urquiza lideró la construcción de la Confederación Argentina luego de Caseros; fue primero su director provisorio y luego su primer presidente hasta 1859 . Puso en funcionamiento lo que Lanteri $(2013,2015)$ entiende como esa etapa experimental del debate entre provincias del primer Congreso.

Durante su gestión como gobernador de la provincia de Entre Ríos, entre 1842 y 1852, dio forma a un nuevo Estado -en este caso el provincial- utilizando como herramientas la construcción de edificios públicos. $^{2}$

Aquí focalizaremos en las transformaciones que se realizaron en su sitio de residencia desde $1850,{ }^{3}$ la estancia San José, cercana a Concepción del Uruguay. Ésta, junto al poblado y al Saladero Santa Cándida, y más tarde junto a la Colonia San José, se fue constituyendo como un espacio de poder del propio Urquiza en términos de apropiación territorial y de construcción identitaria.

En 9 años, en la medida que sustanciaba su poder económico y político, Urquiza fue convirtiendo este espacio extenso sobre el río Uruguay; pasó del sitio del caudillo al lugar del soberano moderno.

Urquiza había sido formado en su casa, ${ }^{4}$ a los 17 años se trasladó a Buenos Aires para estudiar en el Colegio San Carlos, tal como lo habían hecho sus hermanos mayores. El cierre del mismo a fines de 1818 hizo que su experiencia en la ciudad posrevolucionaria fuera breve, ya que regresó a Entre Ríos en julio del año siguiente. No podemos probar que Urquiza tuviera formación en el arte, o al menos en lo que se denominaba el buen gusto. Sí sabemos que se ocupó en conseguir profesionales, que fueran funcionales para sus proyectos, especialmente para operar en su residencia en San José. San José fue proyectado como una unidad edilicia organizada en torno a dos cuerpos estructurados alrededor de patios y dispuestos según un eje este-oeste. El primer cuerpo arquitectónico fue organizado en torno a un claustro. Hacia el este de dicho cuerpo se definió una loggia, limitada por dos torres, lo cual constituye "una fachada" de este edificio exento. En el segundo cuerpo repite la estructura en torno a un patio resolviéndola con una estructura de hierro forjado, que redefine la idea de claustro. Un tercer espacio se organiza con dos ejes: el este-oeste, de menor dimensión, y transversalmente un eje mayor. Un cuerpo arquitectónico limita este patio por el sur. Por el norte se abre un segundo ingreso limitado por un cuerpo arquitectónico y por una capilla que completa el cierre norte. El conjunto se completó con el tratamiento de los jardines anterior y posterior del conjunto. Así, desde el ingreso al este se proyectaron sucesivamente diversos espacios: las plantaciones, el jardín anterior y el posterior, el claustro, el patio del parral, y finalmente el parque del lago, estructurado según el eje este-oeste. Este eje culminaba en el lago artificial y se cerraba con un corral excavado. Tanto el jardín anterior como el posterior se organizaron a partir de una estructura geométrica de ejes, en la que se utilizaron muros bajos como límites. Tanto el espacio que precede al jardín anterior como el que sucede al jardín posterior se organizaron con plantaciones sobre una estricta grilla ortogonal. Cada espacio se organizó además con la estructuración de 
parterres, que le daban características particulares. A la vez se utilizaron estanques, aljibes, quioscos, vasos y pajareras, todo dispuesto simétricamente (Figura $1 \mathrm{a}$ ).

El proyecto fue construido en etapas, ${ }^{5}$ y se han planteado distintas hipótesis sobre quiénes fueron los sucesivos proyectistas de la residencia de Urquiza en San José (Gutiérrez, Viñuales y De Paula, 1971; Ciocchini, Blanco y De Carli, 2011). Plantean tres etapas: la primera entre 1849 y 1853, en la cual Pedro Renom habría construido el primer cuerpo, la segunda entre 1853 y 1856, en la cual Dellepiane lo amplió con la construcción del segundo cuerpo, y la tercera, entre 1857 y 1859, en la que Fossati decoró lo existente y completó la capilla ya iniciada.

En efecto, ya desde 1848 Urquiza estaba preocupado por conseguir un profesional que pudiera resolver cómo dar forma a este espacio de poder desde un saber disciplinar. La construcción de la residencia de Urquiza siempre estuvo asociada a la de otros edificios de Concepción. Cuyás y Sampere ${ }^{6}$ había realizado una gestión en Montevideo a fin de conseguir un profesional que se hiciera cargo del proyecto del Colegio de Uruguay. La idea inicial era contratar a Garmendia, el afamado arquitecto que había construído el Teatro Solís en 1841. Ante la negativa de Garmendia, Cuyás y Sampere recomendó a Renom, pero solo como constructor, ya que no lo consideraba capacitado para el proyecto del Colegio. Sin embargo, ante la falta de disponibilidad de profesionales, Urquiza lo contrató para esta primera parte de la residencia.

Las pruebas sobre la actuación de Dellepiane como arquitecto en San José son contundentes. El registro de las mismas va desde el 4 de febrero de 1853, cuando se le entrega dinero como "arquitecto de la obra", hasta el 25 de noviembre de 1856, momento en que se registra que ya no está al servicio de Urquiza (Ciocchini, Blanco y De Carli, 2011, p. 29). Más allá de las litografías de Thomas Page, quien visitó la residencia en 1855, y del pequeño cuadro de Blanes, probablemente de 1856, las imágenes más interesantes producidas en ese tiempo son la planta y la vista a vuelo de pájaro de San José en el libro de Du Graty. En estas se encuentra el planteo general de San José (Figura 1 B). El grabado tenía por objetivo, según el propio Du Graty, "favorecer los intereses de la Confederación e inspirar confianza en sus instituciones y su gobierno" (Du Graty, 1856, f. 46). 


\section{FIGURA 1}

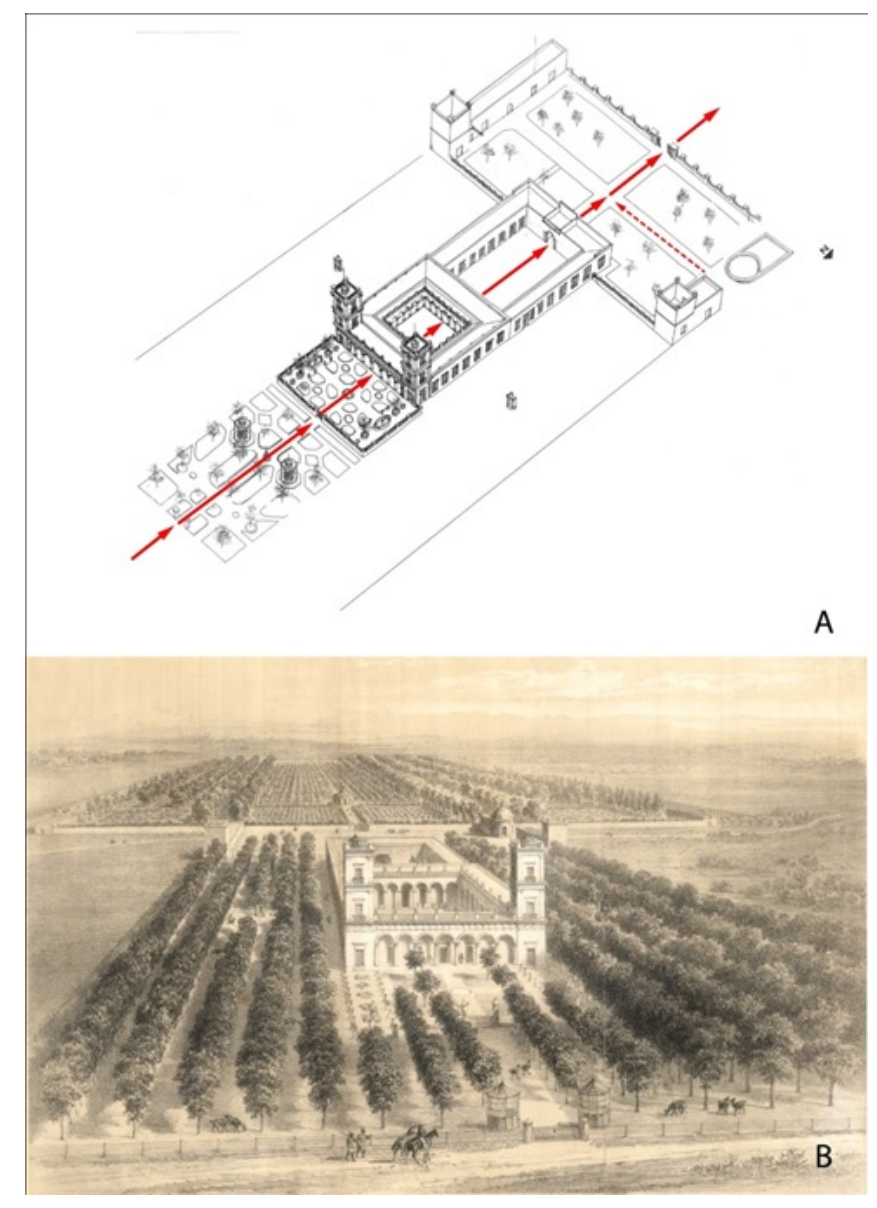

a. Factas, J. (2017). Adaptado de Interpretación gráfica del estado de la construcción de San José en 1858 [Ilustración].

b. Du Graty, A. (2008) [1858]. Adaptado de San José [Ilustración].

La publicación del libro de Du Graty en Francia, en 1858, tenía por objetivo publicitar el país y logar así ser reconocido, hecho que para él implicaría existir en el concierto de las naciones como una república moderna. Incluía el grabado, junto a un plano del chateaux con una leyenda donde describía la fortuna de Urquiza. De ese modo se demostraba cómo en estas lejanas tierras el presidente era un hombre de buen gusto. Para Du Graty era necesario cambiar la imagen que prevalecía en ese momento del país en el exterior, como un territorio dirigido por un caudillo, y transformarla en la de un Estado presidido por un rico e ilustrado presidente capaz de construir un Estado moderno.

La estancia San José fue proyectada inicialmente como lugar del caudillo. Para su ejecución, a falta de un arquitecto, a Urquiza le bastó el constructor Renom, aunque Cuyás y Sampere no lo recomendara para tal fin. La estructura en claustro es parte de ese primer acto. La resolución formal da cuenta de un profesional que, si bien conoce la definición tipológica y apuesta a que esta se resuelva en orden toscano, no cuenta con repertorio académico. ${ }^{7}$

Cuando Urquiza se posiciona como el vencedor de Rosas, es evidente la importancia que implica modificar su propia residencia con el objetivo de transformar su figura de caudillo, para posicionarse como aquel que había superado las luchas entre provincias, como el líder del proceso de construcción de la nueva nación (Dócola, 2017, p. 43). Urquiza, más allá de haber asistido a Palermo en alguna visita anterior, había residido en ella después de vencer a Rosas en Caseros. Resulta inevitable poner en relación el proyecto de San José con el del caserón en Palermo. Frente a la villa rústica sin ornamento de Rosas, San José se plantea como la vieja estructura romana de patios. Si en San Benito (Aliata, 1988) no se mostraban espacios jerárquicos que 
dieran cuenta de la mansión de un soberano, en San José la idea de la sucesión de patios implica cierto orden jerárquico al tiempo que la incorporación de las torres, un elemento de tradición rural, remite a la figura de Urquiza como estanciero.

Si inicialmente San José fue la residencia del caudillo, si la construcción de la logia anterior de los jardines y el segundo cuerpo lo convirtieron en la mansión, serán las últimas intervenciones las que le darán ese carácter de chateaux. ${ }^{8}$ Urquiza necesitaba de un arquitecto que pudiera otorgar atributos a San José, que permitieran su lectura en términos de residencia de un soberano.

Urquiza dio con Fossati gracias a otra actividad en pos de la consolidación estatal. El 4 de setiembre de 1856. Cerruti, cónsul del Reino de Cerdeña, y Urquiza se conocieron en Paraná tras el Tratado de Amistad, Comercio y Navegación entre el Reino de Cerdeña y la Confederación. Urquiza le pidió a Cerruti que, luego de regresar a Buenos Aires, le buscara algún arquitecto para proyectar el templo en Concepción. Cerruti le escribe a Urquiza a fines de 1856 diciéndole que está encargándose de buscar dicho profesional capaz de llevar adelante el proyecto del templo, "pero también otros edificios destinados a ilustrar mayormente el nombre del Presidente Urquiza” (Cerruti, 1856, f.102) Entre estos edificios estaba la culminación de San José.

El 14 de enero de 1857 una nueva carta de Cerruti recomienda a Urquiza la intervención de Fossati como arquitecto. De la carta se pueden extraer algunos datos sobre los antecedentes de Pietro Fossati: su actuación como arquitecto en Egipto y en el Río de la Plata, y su participación en trabajos de infraestructura ferroviaria. Cerruti realizó, de algún modo, un diagnóstico del tipo de profesional que Urquiza necesitaba: un arquitecto y no un idóneo, por lo que volvía a la idea de Cuyas y Sampere

El señor arquitecto don Pedro Fossati es sin duda ninguna un artista de primer orden, y tratándose del plan de un templo destinado justamente con otros edificios a ilustrar mayormente el nombre del Presidente Urquiza, no se necesitaba menos de él, que pueda darle un pensamiento artístico correspondiente a las miras de su promotor. (Cerruti, 1857, f.210)

No tenemos constancia de que Fossati haya sido, como dice Cerruti, el arquitecto del sultán, ${ }^{9}$ ni tampoco que haya estado en El Cairo. Sabemos que Cerruti fue cónsul en El Cairo en el momento en que se construía el Palacio del Sultán (Clemente y Pirjevec, 1980). También conocemos sobre la fama, en estas tierras, del sultán y de su relación con la figura de Urquiza. Alberdi, en sus Cartas Quillotanas, de 1853, cita un texto de Sarmiento en que este relaciona a Urquiza con el mismo sultán, "pero sin su altura, sin el concurso de la ciencia y de la industria europeas" (Alberdi, 1900, p. 58). Por esto resulta interesante la relación planteada por Cerruti, ya que con el aporte de ese europeo, Urquiza podría avanzar en asemejarse a la estatura del sultán.

Fossati había nacido en Morcote (hoy cantón Ticino, Suiza) y construyó los proyectos en Montevideo y Buenos Aires que Cerruti menciona. Estudió ornamento en la Academia de Bellas Artes de Brera (Milán) y conocía las técnicas artesanales del estuco (Dócola, 2017, pp. 212-220). Estas dos cuestiones, y su experiencia, lo habilitaban como un profesional calificado para proyectar decoraciones y dirigir la ejecución de las mismas. De la lectura de sus proyectos podemos afirmar que Fossati manejaba criterios del beaux-arts ${ }^{10}$ : reelaboraba tipos de autor, manejaba las nociones de decoración, enfilade, cuadro, marche, ${ }^{11}$ y las ejecutaba con maestría. Apostaba a un proyecto integral donde espacio, detalles y texturas cobraban la misma importancia. Para ello utilizaba los mejores materiales disponibles y una mano de obra calificada, que le permitió plasmar una arquitectura elaborada. La decoración mediante ornamentos es lo que permitió a Fossati otorgar carácter a la estructura edilicia existente a su llegada para convertirla en el chateaux del soberano.

Según el sistema beaux-arts, el principio de decoración está asociado al concepto del carácter. Quatremère de Quincy había definido en el Diccionario de Arquitectura la noción de carácter con tres acepciones. Una de ellas nos interesa: "sinónimo de propiedad demostrativa de aquello que es el edificio y de lo que debe ser” (Quatremère de Quincy, 2007, p. 116).

Las tres operaciones principales que realiza Fossati fueron: la decoración de las salas, la construcción de la capilla y la realización de la fachada, que iba desde el jardín posterior al patio del parral. Con respecto a la decoración, dio un tratamiento diferenciado desde las salas más decoradas al este hacia las situadas 
al oeste, con menor decoración. Cada habitación tenía un tratamiento particular, ya sea por la elección de algún empapelado, o por la utilización de alguna ornamentación de línea particular en las paredes, o alrededor de puertas y ventanas, o en las boiseries, y lograba, a partir de la decoración de su cielorraso, su mayor individualización. Así, mediante la decoración particular, cada habitación se convierte en un cuadro según los conceptos beaux-arts. El cuarto mayor decorado es el salón con un cielorraso compuesto con espejos comprados en Francia. Le siguen la sala de armas y el billar y el comedor (Figura 2b).

\section{FIGURA 2}

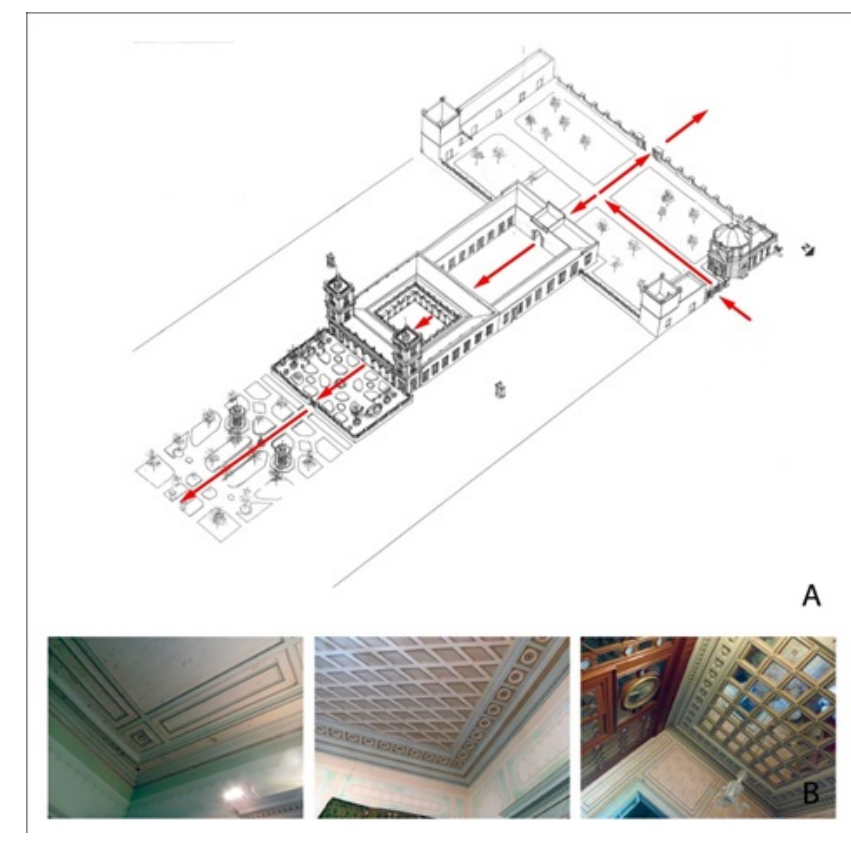

a. Factas, J. (2017). Adaptado de Interpretación gráfica del estado de la construcción de San José en 1858 [Ilustración]. b. Cielorrasos de las salas (imágenes de autoría personal)

La construcción de la capilla, junto a la pulpería y al palomar ya existentes, daba forma a un nuevo ingreso de la residencia. Si antes se ingresaba desde la galería anterior, este acceso por el norte generaba otro recorrido (Figura 2a). El esquema se invertía: se entraba por el portón -o por la capilla o la pulpería- y se avanzaba hasta el centro del jardín. Desde este punto se giraba hacia el este hacia el parque del lago o hacia el oeste hacia la residencia. Si se tomaba ese camino, se sucedían patios, desde el más simple hasta el claustro, estructurados de menor a mayor jerarquía. Los cuartos más alejados del ingreso eran el comedor, el escritorio, la recepción y la sala de juegos y armas, que, a la vez, eran los más decorados. La logia, al este, era el espacio mejor construido en sentido académico; se volcaba al mundo del jardín francés y de allí al parque exótico. A partir de la construcción de este nuevo ingreso, solo algunos ilustres visitantes, como Domingo Faustino Sarmiento, ingresaron por la entrada del este, ya que la del norte fue la usualmente utilizada.

Una de las intervenciones de Fossati fue un pórtico que enmarcaba el ingreso desde el "jardín posterior" al "segundo patio", los que según este esquema se convertían en jardín anterior y en primer patio. La elaborada resolución de esta fachada pone en eje este recorrido, que invierte el esquema de las viviendas urbanas de patios coloniales.

Aliata, cuando trabaja la "transparencia” del mundo privado en lo público en el caserón de Rosas, cita las elaboraciones de Rogister, quien señala relaciones directas entre las plantas de las residencias gubernamentales europeas y los rituales ceremoniales de corte:

que implican un complicado recorrido que gradúa el acercamiento al espacio íntimo del soberano desde los lugares más públicos del edificio. Se establece así una clasificación de la importancia de los visitantes sobre la base del grado de penetración que le es permitido dentro de los aposentos reales (Aliata, 1989, p. 51). 
Esta inversión del esquema de la casa de patios y la construcción de esa marche en términos jerárquicos terminan de definir esa lectura, por parte de Fossati, de Urquiza como soberano y de su residencia como chateaux. La mención de que Fossati había construido el palacio del sultán en Egipto daba sustento a esa potencialidad.

El punto de inflexión en medio del jardín, ahora anterior, es el centro marcado por los bustos de los cuatro conquistadores, que permite tres opciones a quien ingresa: el camino hacia el este hacia el espacio ahora privado del soberano; hacia el oeste, el camino al estanque y a las fiestas públicas, y hacia el sur, a los espacios secundarios de las caballerizas y la tahona. En este nuevo esquema, la galería se convierte en el espacio privado de goce del parque exótico. ${ }^{12}$ Hacia el oeste es el espacio del espectáculo de la figura pública, que halla su punto culminante en el lago. En él se organizaron fiestas venecianas. Incluso la capilla puede pensarse en clave de teatro. Los palcos cerrados, a la manera limeña, no permitían al público saber si Urquiza estaba o no presente. La utilización de un lenguaje simbólico y de ciertas marcas masónicas en el interior de la capilla nos hacen pensar en un doble objetivo: el de generar una capilla privada para el culto público, que se convierte en una capilla tan privada que solo algunos la entienden en clave simbólica. Mientras esto ocurre, el público asiste, sin notarlo, a un oficio más.

Podemos sostener que la decoración y la reorientación del recorrido se convierten en un acto político. La transformación de los espacios se produce de modo dialéctico con las mutaciones del propio Urquiza; se relaciona con el cambio de su sensibilidad arquitectónica, que convierte a San José en el espacio personal e íntimo lo constituye en su lugar identitario como soberano.

\section{LA CONSTRUCCIÓN DE FACHADAS CON ORDEN CLÁSICO: LA DIDÁCTICA DEL BUEN GUSTO EN LA CAPITAL}

Durante los debates constitucionales en la ciudad de Santa Fe se barajaba la idea de que Urquiza sería el nuevo presidente constitucional, por lo cual se discutía si alguna localidad en Entre Ríos, o eventualmente en Santa Fe, serían sitios apropiados para una capital provisoria. La capital transitoria terminó siendo aquella en la que eligieran residir las autoridades nacionales. Y Urquiza eligió residir en Entre Ríos.

Si bien Paraná era la capital de la provincia de Entre Ríos, no era más que una simple aldea nombrada ciudad que no tenía una elite de raigambre colonial, como sí pasaba en el resto de las ciudades capitales.

Por diversas cuestiones, el 13 de diciembre de 1853 se definió Paraná como la capital, pero en marzo de 1854 se federalizó toda la provincia de Entre Ríos. Urquiza se aseguró su sitio de residencia en la estancia San José.

Sobre esa aldea se construyeron edificios que respondieron a los programas del nuevo Estado federativo para convertirlo en capital, teniendo en cuenta su condición de potencialmente efímera; todos esos edificios fueron proyectados por el arquitecto Santiago Danucio. Sus obras son más una arquitectura de fachadas urbanas que planteos arquitectónicos relacionados a tipos considerados apropiados -según el debate de su propio tiempo- para resolver los nuevos programas republicanos.

Danucio llegó a Paraná, procedente de Montevideo, a inicios de 1854 portando en mano dos cartas de recomendación dirigidas a Benjamín Victorica, agente del gobierno y yerno de Urquiza. Una de las cartas está fechada en Montevideo en enero de 1854, atribuida a Pedro de Angelis (De Angelis, 1854) la otra fechada en Rosario el 25 de enero de 1854, firmada por Nicolás Martínez Fontes (Martínez Fontes, 1854). Ambos coincidían en definirlo como arquitecto de primer orden. De Angelis informaba que Danucio había decidido emprender viaje por su cuenta de Montevideo a Paraná. De Angelis basó su recomendación en las repetidas pruebas que había dado en Montevideo, de las cuales se hace cargo como testigo, y de sus antecedentes. Definió que podía dedicarse a obras públicas, lo cual podía ser muy útil en estas circunstancias. Por su parte, Martínez Fontes lo definió como señor italiano, y hacía referencia a su condición de arquitecto, pero sobre 
todo como sargento mayor de Infantería en el Ejército del Estado Oriental, calificándolo como a su "político federal a toda prueba".

En Paraná, Danucio proyectó y construyó sucesivamente los edificios de los poderes del Estado para la Capital: la casa de Gobierno en 1854, probablemente la Cámara de Diputados en 1855, el Senado en 1858-59; todos ellos en relación con la plaza. Esta se constituyó en el espacio de poder de la República, resignificándola como el espacio público institucional de la ciudad, centro de la capital. En esa misma plaza proyectó la casa de Urquiza entre 1856 y 1857, quien pretendía hacerse visible en este mismo espacio.

Danucio había vivido en la Montevideo donde Zuchi había proyectado la plaza Independencia, por lo cual conocía la idea de construir un conjunto unitario, una plaza porticada; sin embargo, su propuesta para Paraná no contemplaba dicha operación. La construcción de la plaza se produjo como una serie de intervenciones independientes en sus límites. La cuestión era cómo construir los edificios del naciente Estado en ese centro de poder de la República.

Durante la Confederación, "las provincias comenzaron a entenderse y a asumirse en una forma federal y republicana y las autoridades a construirse y autorrepresentarse, y a legitimarse como una dirigencia política con proyección nacional" (Lanteri, 2015, p. 21). Para la autora, la ciudad capital de la Confederación se convirtió en un "laboratorio privilegiado para avistar la manera en que el ideario constitucional se plasmó en una realidad por lo demás múltiple y compleja” (Lanteri, 2015, p. 21).

Llevar adelante un gobierno republicano implicaba enfrentar nuevos mecanismos, hacerlo menos personalista, aunque el presidente tuviera un lugar central. Lanteri describe las tensiones a las que se veía sujeto Urquiza, entre el viejo modo de gobernar y el nuevo sistema que intentaba llevar adelante. En este marco, postula que el Congreso se constituyó en una "institución clave de encuentro, selección, enseñanza e integración de las elites políticas provinciales" (Lanteri, 2015, p. 21), al mismo tiempo que destaca los acuerdos que se llevaban adelante por fuera de las cámaras. En una carta de Victorica a Urquiza esto queda claro:

Mi casa, o mejor dicho la casa de V. E., es el cuartel general de la mayoría, todas las noches nos reunimos a conferenciar y a decidir 13 diputados y casi un número igual de senadores. Me cuestan algunas botellas de cerveza y cigarros, y otros obsequios, cosa indispensable, pero estamos bien organizados de manera que cuando vamos a las cámaras, llevamos el triunfo hecho (Lantieri, 2015, p. 159).

De ese modo, las casas de quienes lideraban las diferentes y cambiantes facciones, pero en especial la casa de Urquiza, que él generalmente no habitaba, se constituían en los espacios de debate y consenso. Si seguimos esa idea de "laboratorio" planteada por Lanteri, y tenemos en cuenta la condición efímera de la Capital, y pensamos en la escasez de recursos y en la falta de cierta formación de Danucio, podemos explicar por qué para la capital bastaba con la simplicidad de las propuestas de sus edificios públicos.

Por un lado, la Casa de Gobierno remite tipológicamente a un palacio urbano. ${ }^{13}$ Por otro, la resolución del planteo de Diputados mediante la utilización de un frontis fuera de escala, colocado en todo en el frente del edificio, remite a un intento por otorgar carácter republicano a una sala de representantes de este laboratorio experimental. Si bien Danucio había vivido 11 años en el Río de la Plata, no parece conocer los debates planteados en Buenos Aires (Aliata, 2006) y Montevideo (Aliata, 2009) para la construcción de las Cámaras en un sentido republicano. Danucio descartó la utilización de salas específicas con tipologías de matriz semicircular, las que constituirían espacios de opinión en el sentido benthamiano. ${ }^{14}$ Para Diputados planteó la tradicional estructura basilical con tres naves, a la manera de Sala de los Comunes en Londres, estructurando la sala a través del mobiliario, y mandando al público a las naves laterales. En Senadores, optó por una única sala mandando al público a los pequeños balcones perimetrales. Prescindió, entonces, de la idea de matriz semicircular, o sencillamente es posible que no la conociera. Lo que le interesaba no era la forma del debate, el cual se garantizaría con el uso de una matriz semicircular, sino que apostó a la imagen de un espacio republicano. 
Si observamos las escasas imágenes de Paraná, los grabados de Burmeister y su compañero de viaje Göering, ${ }^{15}$ y otras imágenes posteriores, ${ }^{16}$ en el momento de la llegada de Danucio a la ciudad, en las construcciones persisten aún los techos de teja con pendiente hacia la calle, fachadas continuas con una estética poco desarrollada, sin la utilización del orden arquitectónico. Frente a esto, la utilización por parte de Danucio en todas sus obras de un vocabulario clásico conmovió a Burmeister, quien residió en Paraná entre 1858 y 1859 , y a Navarro, un joven diputado por Catamarca.

Burmeister, formado en Prusia y con una sólida base académica, estaba educado en el gusto por la antigüedad clásica y el neorrenacimiento. Realizó una valoración sobre los diferentes edificios de la capital. De sus descripciones se infiere que conocía los estilos; podía discernir si se trataba de un orden toscano, jónico o corintio, y además reconocía las sutilezas de un gótico toscano como el de la proyectada iglesia San Miguel. Burmeister, no solo describía los edificios realizados en Paraná, sino que se convirtió en un crítico. Al referirse a la Casa de Gobierno afirmaba

El todo atestigua la mano maestra de un estudioso en el arte de la construcción y hace honor a su proyectista, quien ha ejecutado todos sus trabajos con elegancia y buen gusto. ...Alegra encontrar una obra que tanto agrada, lejos, en el interior de un país en parte aun solo muy escasamente poblado (Burmeister, 2008, T I, p. 369).

También declamaba, según su entender, que esta obra estaba construida "en todo conforme con las reglas del arte arquitectónico" (Burmeister, 2008, T I, p. 370). Lo que consolaba a Burmeister, en el medio de este interior pobre y sin arquitecturas que le interesasen, era esa arquitectura de fachadas. Nada remitía, en su descripción, a alguna particularidad en el diseño de sus espacios interiores, en sus salas, en su escalera. De ese modo, las fachadas urbanas, construidas según los principios del orden arquitectónico clásico, de alguna manera educaban a diputados y a senadores en el gusto, e intentaban cambiar esa sensibilidad arquitectónica mediante una didáctica en torno a la plaza. Ahora, al volver a sus provincias, los diputados, los senadores y todos los visitantes de Paraná llevarían ese buen gusto, esa nueva sensibilidad arquitectónica, que el gobernador de Tucumán afirmaba no existía, y que para Zucchi los habitantes del Plata solo podrían incorporar por milagro.

Navarro describió el edificio de Diputados el día del inicio de las sesiones preparatorias. La algarabía de Navarro parece tener que ver más con el lujo de la decoración y de los materiales utilizados que con la resolución espacial. Le llamaba la atención la utilización del orden arquitectónico en su interior: "las columnas son redondas y con bases llenas de molduras y chapiteles cerca de la techumbre" (Cañete, 2004, p. 26). Era tal la pobreza de estos espacios interiores que esto resulta destacable. De algún modo Danucio extiende al interior esa idea de que el orden clásico, junto al lujo del mobiliario, valorizaba el espacio de labor parlamentaria y educaba en el buen gusto.

La plaza no había sido más que un espacio sin tratamiento. En 1854 De Moussy la describía como un "desierto de yerba y de polvo", en el que, "después de concluida la Casa de Gobierno, la administración la hará plantar y adornar", para hacer de ella "un paseo público muy agradable”. (De Moussy, 1854). La litografía de Göering sobre la Casa de Gobierno (Figura 3) nos muestra la plaza a fines de la década del 50 ya con árboles plantados en el perímetro, con rejas y con tratamiento del solado en el perímetro y las diagonales marcadas. 
FIGURA 3

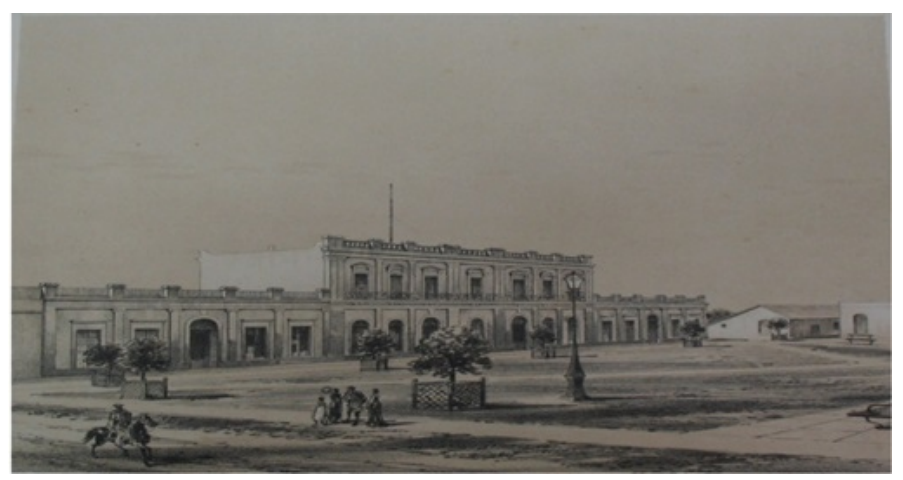

De Göering (1858) en Burmeister (1879). Adaptado de Casa del Gobierno nacional, Paraná [Litografía]. Vues Pittoresques, pl. IV fig. 7.

La plaza se constituía en el escenario de las fiestas, siguiendo la tradición instalada por Rosas para Buenos Aires. Zucchi había realizado escenografías efímeras ornamentales para las mismas. Como señala Munilla Lacasa (2009), estas desempeñaron un papel fundamental como parte de las políticas pedagógicas del Estado rosista. La fiesta de mayo en Paraná, de 1858, fue narrada por Burmeister: "En el centro de la plaza se había erigido una especie de templo de honor, imitación del famoso monumento de Lysicrates de Atenas, aunque este solo se componía de listones y de bramante blanco pintado" (Burmeister, 2008, TI, pp. 379-382). Estas habían sido realizadas por el Sr. Casanova, escenógrafo del teatro. En Paraná no se necesitaba una figura como Zucchi, Danucio no era experto en escenografías temporarias, era constructor de edificios para el gobierno, y de fachadas urbanas para la capital efímera. Las fachadas de los edificios de Danucio se constituían en el marco permanente, en esta didáctica del buen gusto que instalaba la idea del orden clásico como republicano.

Más allá de esto, un acontecimiento nos da cuenta de qué escenario constituían los proyectos de Danucio en relación con la plaza. Burmeister, una vez más, describe un evento, la parada militar realizada al día siguiente de la fiesta en la plaza. Urquiza "se hallaba en brillante uniforme, rodeado de un sequito militar numeroso [14.000 soldados], de los más altos empleados civiles y enviados extranjeros, en el balcón de su casa" (Burmeister, 2008, TII, p. 374). La casa de Urquiza y la plaza se constituyeron en el escenario de demostración de poder ante la escindida y enemiga Buenos Aires, y en espacio de toma de conciencia de la unidad de la Confederación Argentina. La fachada de la casa de Urquiza, enmascaraba uno de los principales lugares de la toma de decisiones de diputados y senadores. La figura de Urquiza desde el balcón se presentaba como la de un soberano; la arquitectura daba sostén a lo litúrgico.

\section{Conclusiones}

Este trabajo ha demostrado cómo, ante la escasez de técnicos en la Confederación, se apeló a algunos extranjeros disponibles en las tierras del Plata, que decían ser profesionales, ${ }^{17}$ en tanto portadores del buen gusto. Hemos profundizado sobre dos arquitectos centrales en este proceso, Pietro Fossati y Santiago Danucio, quienes, a partir de sus diferentes perfiles, fueron funcionales y suficientes para la concreción del lugar del soberano moderno y para la construcción del espacio de la capital efímera. Esas arquitecturas instalaban una didáctica del gusto para replicar en las provincias. En cambio, para generar el lugar del soberano se necesitaba apelar a un profesional formado en los principios académicos. Con el manejo de conceptos beaux-arts, Fossati permitió transformar la residencia del caudillo en el chateaux del soberano moderno.

Luego de la incorporación de la provincia de Buenos Aires a la Confederación Argentina y de la elección del presidente, en la que resultó vencedor Derqui, el equilibrio entre los Estados provinciales se derrumbó. La capital finalmente se trasladó a Buenos Aires en 1861 y Paraná volvió a ser una aldea. El débil carácter arquitectónico del edificio de Diputados, marcado por la utilización de un frontis que remite al modelo 
democrático, y su falta de resolución a través de tipos arquitectónicos específicos -como lo eran los espacios armados como anfiteatros-, que se vincularan a los nuevos programas republicanos que se estaban poniendo en marcha, permitió que los edificios de la capital, al dejar de cumplir ese rol, albergaran otros programas.

Urquiza se retiró a su chateaux a ejercer como un soberano. Su casa en Paraná se vendió en 1860 a la Nación como casa del presidente. Aun cuando solo mantenía el mando de los ejércitos confederados y supuestamente no tenía el poder, desde su espacio privado seguía, en parte, controlando los destinos del país. El chateaux ahora reemplazaba a su casa de Paraná. Su última obsesión, luego de dotar al chateaux del tal carácter, fue modernizarlo mediante la instalación de cañerías de agua e incorporó los más nuevos artefactos. El jardín y su lago, con la compra del barco, se convirtieron en el espacio público del espectáculo del soberano, reemplazando el teatro del control de las tropas desde el balcón. La fiesta en los jardines reemplazó a las fiestas patrias. Sarmiento, ya presidente, visitó a Urquiza entre el 3 y el 7 de febrero de 1870 para conmemorar la batalla de Caseros. Fue recibido en Concepción del Uruguay y en el Palacio San José con la pompa del soberano. Sarmiento finalmente reconoció al hombre civilizado, lejano a aquel que había desprestigiado, primero desde Chile y luego desde Buenos Aires. Urquiza había logrado la estatura del sultán, gracias a los trabajos de Fossati.

Urquiza fue asesinado en abril del mismo año en su chateaux, y en ese acto se cierra el espacio del soberano. Sería enterrado, tal como lo había previsto, en su panteón al héroe en la iglesia de Concepción, también proyectada por Fossati.

\section{REFERENCIAS}

Aliata, F. (1989). Lo privado como público. Palermo de San Benito: un ejercicio de interpretación. Revista de la Sociedad Central de Arquitectos, (144) $44-53$.

Aliata, F. (2006). La ciudad regular: arquitectura, programas e instituciones en el Buenos Aires posrevolucionario, 1821-1835. Buenos Aires: Prometeo.

Aliata, F. (2009). Carlo Zucchi: arquitectura, monumentos, decoraciones urbanas 1826-1845. La Plata: Ediciones Al Margen.

Bosch, B. (1980). Historia de Entre Ríos, 1520-1969. Buenos Aires: Plus Ultra.

Bosch, B. [1971] (1984). Urquiza y su tiempo. Buenos Aires: Editorial Universitaria de Buenos Aires.

Cañete, C. (2004). Estampas: el palacio de Urquiza en Paraná y su monumento en el parque. Paraná: Trafico de arte.

Ciocchini, H., Blanco, G., y De Carli, L. (2011). El palacio de la memoria: hipótesis sobre la simbología de la ornamentación en la residencia del General Urquiza. Buenos Aires: Editorial Universitaria de Buenos Aires.

Clemente, V. \& Pirjevec, G.(1980). Cerruti, Marcello. En Dizionario biografico degli italiani - Volume 24. Treccani. Recuperado de http://www.treccani.it/enciclopedia/marcello-cerruti_(Dizionario-Biografico)/

Dócola, S. (2017). Espacios de poder para La Confederación Argentina. La capital, el puerto y el lugar del soberano. 1854 - 1859 (Tesis doctoral). Recuperada de http://sedici.unlp.edu.ar/handle/10915/64188

Gutiérrez, R., De Paula, Alberto S. J., y Viñuales, G. (1971). La arquitectura de la Confederación Argentina en el litoral fluvial (1852-1862). Resistencia: Departamento de Publicaciones e Impresiones de la Universidad Nacional del Nordeste.

Lanteri, A. L. (2015). Se hace camino al andar. Dirigencia e instituciones nacionales en la Confederación Argentina, 1852-1862. Rosario: Prohistoria Ediciones.

Munilla Lacasa, M. L. (2009). De espectáculos y políticas: la actuación de Carlo Zucchi en las fiestas del rosismo. En F. Aliata (Ed), Carlo Zucchi: arquitectura, monumentos, decoraciones urbanas 1826-1845 (pp. 147-168). La Plata: Ediciones Al Margen.

Pérez Alonso, P. (2008). El gusto estético. La educación del (buen) gusto. Estudios sobre Educación (14), 11-30. Recuperado de https://studylib.es/doc/5166377/el-gusto-est\%C3\%A9tico.-la-educaci\%C3\%B3n-del--buen--g usto 
Rabbat, N. (2005). A mosque and an imperial dream. Recuperado de http://web.archive.org/web/20130624091048 /http://weekly.ahram.org.eg/2005/756/special.htm

Rato De Sambuccetti, S. (1999). Urquiza y Maua: el mercosur del siglo XIX. Buenos Aires: Ed. Macchi

Tirado, J., y Mora, M. (2002). El espacio y el poder: Michel Foucault y la crítica de la historia [versión electrónica]. Espiral, IX(25), 11-36. Recuperado de https://www.redalyc.org/pdf/138/13802501.pdf

\section{FuenTES}

Alberdi, J. B. (1900). Cartas quillotanas:polémica con Domingo F. Sarmiento. Buenos Aires: Rosso.

Burmeister, H. (1879). Vues pittoresques de la République Argentine. En Atlas Physique de la Republique Argentine. Buenos Aires: Coni

Burmeister, H. [1861] (2008). Viajes por los Estados del Plata. Buenos Aires: Academia Nacional de la Historia.

Cerruti, M. (14/1/1857). Carta a Justo José de Urquiza. Sala VII. Archivo Urquiza. 1857. Tomo 107. Folio 210. Archivo General de la Nación. Buenos Aires. Argentina.

Cerruti, M. (30/11/1856). Carta a Justo José de Urquiza. Sala VII. Archivo Urquiza. 1856. Tomo 107. Folio 102. Archivo General de la Nación. Buenos Aires. Argentina.

De Angelis, P. (01/1854) Carta de recomendación (atribuida a) a Benjamín Victorica..Sala VII. Archivo Victorica. Doc. 12062. Archivo General de la Nación. Buenos Aires. Argentina.

De la Vega, A J. (4/02/1857) Carta a Tomás Guido. Sala VII. Archivo Guido. Folio 169. Archivo General de la Nación. Buenos Aires. Argentina.

De Moussy, V. (1854). Folletín Cuadro general de la ciudad de Paraná y de sus alrededores, vegetación y cultivo. Constitución geológica del suelo considerada agrícola e industrialmente. El Nacional Argentino. $\mathrm{N}^{\circ} 162$. Paraná, 24/12/1854, Nº 163. Paraná, 28/12/1854 y Nº 164. Paraná, 31/12/1854.

Du Graty, A. (4/11/1856) Carta a Urquiza. Sala VII. Archivo Urquiza, tomo 107, folio 46. Archivo General de la Nación. Buenos Aires. Argentina.

Du Graty, A. [1858] (2008). La Confederación Argentina. Academia Nacional de la Historia Buenos Aires.

Martínez Fontes, N. (25/01/1854). Carta de recomendación a Benjamin Victorica. Sala VII. Archivo Victorica. Doc. 12061. Archivo General de la Nación. Buenos Aires. Argentina.

Quatremère de Quincy, A. [1832] (2007). Diccionario de Arquitectura (Edición Voces teóricas. J. Sarquis). Buenos Aires: Poiesis. Nobuko

\section{Notas}

1 Este diagnóstico lo realizó en dos cartas, ambas se encuentran traducidas (Aliata, 2009, pp. 167-199).

2 Entre otras las Comandancias, escuelas en ciudades y en la campaña, teatros, iglesias y capillas (Bosch, 1978, p. 184).

3 Solo se ausentó de San José durante la campaña del ejército Grande, y en la preparación del Congreso de Santa Fe, luego para la apertura y la clausura de las sesiones del Congreso Nacional mientras ejercía el rol de presidente. También se ausentó en la Misión ante el presidente Carlos López en Asunción del Paraguay, durante las campañas de Cepeda y Pavón y en contadas ocasiones, las cuales no se extendían más que una semana (Ciocchini, Blanco y De Carli, 2011, p. 29).

4 Su primera educación se realizó en su casa, con su madre María Cándida García y Monzón y, supuestamente, cursó los estudios primarios comunes a la época impartidos por un sacerdote (Bosch, 1980).

5 Esta descripción da cuenta del estado del proyecto en el momento de la inauguración del lago realizado en la década de 1860 y de la colocación de la pérgola en el patio de parral realizada en 1868. Las fotografías tomadas alrededor de 1873 por Saturnino Mazzoni dan cuenta de este estado.

6 Antonio Cuyás y Sampere fue socio de Justo José de Urquiza y administró algunos campos que tuvo en sociedad con él. Se convirtió en el representante comercial de Entre Ríos en la ciudad sitiada de Montevideo, que era abastecida solamente desde esa provincia. En 1850 representó a Urquiza en las negociaciones con el Gobierno de la Defensa de Montevideo y con el Imperio del Brasil (https://es.wikipedia.org/wiki/Imperio_del_Brasil). 
7 Se entiende por orden arquitectónico a la utilización de un vocabulario clásico formado por elementos de formas fijas (columnas, entablamento, frontis) articulado por reglas estrictas de posición, proporción y matriz geométrica: los cinco órdenes son toscano, dórico, jónico, corintio y compuesto.

No tenemos datos sobre la formación de Renom. Afirmamos que no tiene formación académica a partir de nuestra lectura espacial del propio proyecto, ya que no aplica las normas de la disciplina con las cuales se proyectaba en el siglo XIX.

8 En una carta escrita desde Montevideo, Federico Reyes expresa que Urquiza está en su chateaux (Cit. Rato de Sambuccetti,1999, p. 245). En las vistas que publica Du Graty también se utiliza el término chateaux. Es por eso que utilizaremos este término en lugar de palacio.

9 Mehmet Alí o Mehemet Alí (nacido en c. 1769 y muerto en 1849). Es considerado como el fundador del Egipto moderno. El palacio del Sultán es atribuido a Pascal-Xavier Coste (Rabat, 2005).

10 A modo de simplificación podemos plantear que para mediados de siglo XIX, en general en el mundo occidental, se proyectaba desde dos modos diferentes el sistema beaux-arts o el sistema politécnico. El primero, sostenido por la Academia Francesa, l' Ecole de Beaux-arts y difundido por las demás Academias, basaba sus enseñanzas en una serie de principios básicos normados. Ver nota 19. El segundo, definido en l'Ecole Politecnique tenía que ver más con un método racional de base científica.

Sostenemos que Fossati tenía conocimiento del sistema beaux-arts, no solo por haber constatado su inscripción en la Escuela de Ornamento de la Academia de Bellas Artes de Brera en Milán, sino por la aplicación de dichos principios en sus obras en Montevideo y en particular en la Iglesia de Concepción y en el propio San José (Dócola, 2017, pp. 227-231 y pp. 233-238).

11 Quatremère de Quincy publicó el Dictionnaire d'architecture de la Encyclopédie méthodique, entre 1788 y 1825 (Quatremère de Quincy, 2007), donde da cuenta de la mayoría de los conceptos que de algún modo regían el modo de proyectar según los principios del beaux-arts. En el texto hemos utilizado algunas nociones cuyo sentido podemos simplificar para el lector no familiarizado con los términos de tradición académica arquitectónica. Nos hemos referido a la noción de marche cuando hablamos de la cualidad de un edificio de ser recorrido de una manera secuencial; a la de enfilade cuando referimos a una serie de espacios alineados en un eje, donde las puertas están secuenciadas en relación con ese eje, lo cual permite visualizar los diferentes espacios a través del mismo; llamamos cuadro a la definición de cada espacio en sí mismo.

12 Si seguimos el suceso del asesinato de Urquiza en abril de 1870 vemos que él se encontraba en el pórtico y los asesinos ingresaron por la puerta norte. Estos no encontraron resistencia, por lo cual los filtros eran más simbólicos que prácticos.

13 A partir del 1400, en Florencia, se implementa un tipo de resolución de fachadas para palacios urbanos que se repetirá en los próximos siglos. Estas, en general, se resuelven construyendo el muro urbano continuo sobre la línea de edificación, apelando a la simetría y a la utilización del orden arquitectónico que organiza la fachada. Cuando afirmamos que el carácter de la Casa de Gobierno es el de un palacio urbano, nos referimos a esa resolución frente a las casas de Paraná.

14 Nos referimos a un espacio de matriz semicircular, similar a los anfiteatros, utilizado en los clubes jacobinos de asambleas primarias. Esta forma permite hacer visible la igualdad política, eliminando las jerarquías. El modelo de Bentham se presentaba como máquina perfecta para establecer los debates (Aliata, 2006, pp. 225-254).

15 Burmeister viajó con Göering y registraron paisajes urbanos, rurales o suburbanos. Burmeister, ya instalado en Buenos Aires y desempeñándose como director del Museo Público, publicó en 1879 su Atlas Physique de la Republique Argentine, cuya primer sección Vieux Pittoresques tiene 14 láminas de gran tamaño, con cuatro imágenes de Paraná.

16 Fotografías existentes en el Museo Martiniano Leguizamón Ciudad de Paraná. Colección Cirilo Amancay Pinto.

17 Decíamos que decían ser profesionales, ya que no exhibían sus títulos. 